\title{
INTEGRAÇÃO AMAZÔNICA PELA NAVEGAÇÃO FLUVIAL: DO TRATADO DE COOPERAÇẢO AMAZÔNICA À CRISE DA INICIATIVA PARA INTEGRAÇÁO DE INFRAESTRUTURA REGIONAL SUL-AMERICANA
}

\author{
André de Paiva Toledo ${ }^{1}$ \\ Escola Superior Dom Helder Câmara (ESDHC) \\ Marcos Edmar Ramos Alvares da Silva ${ }^{2}$ \\ Pontifícia Universidade Católica de Minas Gerais (PUC-MINAS) \\ Artigo recebido em: 04/11/2020. \\ Artigo aceito em: 02/12/2020.
}

\section{Resumo}

Este artigo dedica-se a analisar a importância da navegação fluvial para a integração regional amazônica. Com o desenvolvimento do direito internacional do meio ambiente, a preservação da Amazônia torna-se objeto de interesse da humanidade, em razão de suas riquezas naturais, diversidade cultural e importância ecossistêmica. Como reação ao discurso de internacionalização, os Estados amazônicos subdesenvolvidos adotam o Tratado de Cooperação Amazônica para reafirmar a soberania territorial e estimular a cooperaçáo regional. Entretanto, o Tratado também pode ser identificado como base nor- mativa para a integraçáo regional. Para tanto, destaca-se a navegação fluvial, que, por sua vez, depende de investimentos em infraestrutura. A fim de suprir essa demanda, a Iniciativa para a Integração de Infraestrutura Regional Sul-Americana, vinculada à União das Naçôes Sul-Americanas, apresenta-se como alternativa multilateral de investimentos nesse setor. Contudo, a modificação do contexto político continental, marcado por um exacerbado conservadorismo, tem inviabilizado essa alternativa de integração regional. Analisa-se historicamente o processo de integração por meio da navegação

1 Doutor em Direito pela Université Panthéon-Assas Paris 2. Mestre e Bacharel em Direito pela Universidade Federal de Minas Gerais (UFMG). Professor do PPGD da ESDHC. ORCID: https://orcid.org/0000-0002-9258-0027 / e-mail: depaivatoledo@gmail.com

2 Doutorando em Direito Internacional pela PUC-MINAS. Mestre em Direito Ambiental e Desenvolvimento Sustentável pela ESDHC. Advogado. E-mail: Marcos Edmar Ramos Alvares da Silva 
fluvial, a fim de entender a aparente contradiçáo entre o projeto de cooperação amazônica, lançado como resposta às pressôes internacionais pela preservação da Amazônia, e seu abandono, quarenta anos depois, justo quando se reforçam tais pressões.

Palavras-chave: Amazônia; IIRSA; Integração regional; TCA.

\section{AMAZONIC INTEGRATION BY FLUVIAL NAVIGATION: FROM THE AMAZONIC COOPERATION TREATY TO THE CRISIS OF THE INITIATIVE FOR INTEGRATION OF REGIONAL INFRASTRUCTURE IN SOUTH AMERICA}

\section{Abstract}

This article is dedicated to analyzing the importance of river navigation for Amazonian regional integration. In the face of the emergence of International Environmental Law, the Amazon, whose preservation becomes the interest of humanity, due to its natural wealth, cultural diversity and ecosystemic importance. As a reaction to the internationalization discourse, the underdeveloped Amazonian States adopt the Amazon Cooperation Treaty to reaffirm territorial sovereignty and encourage regional cooperation. However, the Treaty can also be identified as a normative basis for regional integration. To this end, river navigation stands out, which, in turn, depends on investments in infrastructure. In order to meet this demand, the Initiative for Integration of Regional Infrastructure in South
America, linked to the Union of South American Nations, presents itself as a multilateral alternative for investments in this sector. However, the change in the continental political context, marked by an exacerbated conservatism, has made this alternative of Amazonian integration unfeasible. The process of integration, through river navigation, is historically analyzed, in order to understand the apparent contradiction between the Amazonian cooperation project, launched in response to international pressures for the preservation of the Amazon, and its abandonment, forty years later, justly when such pressures are reinforced.

Keywords: ACT; Amazon; IIRSA; Regional integration. 


\section{Introdução}

O fim dos anos de 1960 correspondeu ao momento histórico de aumento da ocorrência de significativos danos ambientais transfronteiriços, o que levou à inserção do tema ambiental na agenda de negociaçóes internacionais, especialmente no âmbito das Naçôes Unidas. Naquele momento, chamaram a atenção da sociedade internacional questóes relativas à poluição, notadamente a poluição atmosférica e marinha. A constatação de que o modelo econômico ambientalmente predatório, adotado universalmente por ambos os blocos envolvidos na chamada Guerra Fria e cobiçado por aqueles que ainda compunham o Terceiro Mundo, afetava significativamente a composiçáo da atmosfera e do mar, causando consequentemente marés negras, chuvas ácidas, diminuição da camada de ozônio e doenças respiratórias, significou o momento de inflexão de um processo que se iniciara livremente durante a Revolução Industrial.

No contexto de construção do direito internacional do meio ambiente, a Amazônia passou a estar cada vez mais presente como objeto de discussão e interesses de diversos atores globais, que se dedicavam a construir o significado de desenvolvimento sustentável. Isso se devia ao fato de a Amazônia consubstanciar concretamente a idealização da integridade ambiental originária em sua mais profunda riqueza. Se havia um ponto do planeta em que ainda era possível conservar a natureza em sua mais ampla diversidade, esse local era a Amazônia. Não se trata, entretanto, de um ponto insignificante, mas de uma extensa área, correspondendo a milhóes de quilômetros quadrados no coração da América do Sul ou 40\% do território terrestre de todo aquele continente.

Simultaneamente, a Amazônia é espaço de riqueza cultural, onde se encontram tradicionalmente diversas comunidades humanas que têm, ao longo do tempo, estabelecido uma relaçâo íntima com o meio ambiente natural. Dos conhecimentos tradicionais associados às riquezas naturais amazônicas, tem-se descoberto paulatinamente suas riquezas econômicas e estratégicas. Sabe-se que, além da diversidade biológica, que é cada vez mais interessante para importantes setores econômicos internacionais, concentram-se, no espaço amazônico, jazidas de importantes minerais e fantástica massa de água doce, o que faz desse espaço a maior reserva hídrica do mundo. Na Amazônia, encontra-se a maior bacia fluvial do mundo.

A dependência ecossistêmica existente na Amazônia entre biodiversidade e água faz que a noção de bacia hidrográfica amazônica se torne o principal elemento da compreensão de sua importância ecológica local, regional e global (TIILO NETO, 2009). Náo se pode compreender os desafios da preservaçáo ambiental na 
Amazônia desconsiderando a dependência desse ecossistema de seus cursos d'água.

A partir do momento em que a pauta ambientalista é definitivamente inserida nas negociaçóes internacionais, fenômeno que impulsiona e é impulsionado por uma forte mobilização da opinião pública mundial - especialmente nos países desenvolvidos -, os Estados em desenvolvimento ${ }^{3}$ em cujo território se encontra parte da Amazônia, que compóem a Pan-Amazônia ${ }^{4}$, articularam-se para desenvolver um arcabouço jurídico internacional fundado nos princípios da soberania territorial e da cooperação regional. Daí resultou o Tratado de Cooperaçâo Amazônica, celebrado em 1978.

Entre os mecanismos de cooperação amazônica, destaca-se a integração por meio da navegação fluvial, aproveitando-se do volume significativo dos cursos d'água ali existentes. Com efeito, a bacia hidrográfica amazônica não funciona apenas como elemento central da dinâmica ecossistêmica, mas também se destaca como base de integração histórica dos povos daquela regiáo, tendo em vista que os deslocamentos humanos, assim como a circulação da produção local - seja ela com base na exploração da borracha, castanhas ou outros cultivos - têm sido majoritariamente realizados por meio da navegação fluvial. Logo, não há como tratar plenamente da integração regional sul-americana sem examinar o papel exercido pela navegação fluvial amazônica (CARVALHO; SILVA, 2015).

Com base nesse postulado, analisa-se o papel do transporte fluvial como instrumento prioritário de um processo de integração regional amazônico, que aprofunde os mecanismos de cooperaçáo previstos no Tratado de 1978. Diante disso, questiona-se a existência de instrumentos internacionais em vigor capazes de impulsionar esse processo de integração amazônica com base no fortalecimento da navegação fluvial. Neste ponto, identifica-se a Iniciativa para a Integração da Infraestrutura Regional Sul-Americana (IIRSA) como programa multilateral capaz de impulsionar a necessária conjuntura de infraestrutura para a navegação fluvial, que seja a base da integração regional dos Estados da Amazônia. Por fim, analisa-se o atual cenário de enfraquecimento das iniciativas de integração regional sul-americana diante da emergência de forças políticas conservadoras, que impacta diretamente as iniciativas de integração amazônica pela navegação fluvial.

Essa mudança do resultado da correlação de forças políticas no continente sul-americano, que tem inviabilizado a alternativa de integração amazônica por meio de investimentos em infraestrutura, apresenta-se como uma aparente

3 A França, que é um Estado amazônico desenvolvido, ficou de fora da articulação dos demais países em favor da celebraçâao do Tratado de Cooperação Amazônica.

4 Em respeito à decisão teórica adotada pelo Grupo de Pesquisa Estratégica sobre a Pan-Amazônia, existente no âmbito do Programa de Pós-Graduação em Direito da Escola Superior Dom Helder Câmara, somente trataremos de Pan-Amazônia o contexto em que fizer parte todos os Estados amazônicos, inclusive a França. 
contradição, tendo em vista que todo o projeto de cooperação amazônica, lançado pelo Brasil em $1977^{5}$, tinha como finalidade dar uma resposta amazônica às pressôes internacionais por preservação ambiental, que se constituíram como desdobramentos políticos da Conferência das Nações Unidas sobre Meio Ambiente Humano, ocorrida na Suécia, em 1972. Justamente, no momento em que essas pressôes ambientalistas se reforçam, quarenta anos depois, verifica-se o abandono de uma importante iniciativa de realização do projeto de integração amazônica.

Analisando-se historicamente o processo de criação e aplicação do sistema jurídico de cooperação amazônica, identifica-se a importância da navegação fluvial para sua efetividade. Em seguida, constata-se a necessidade de investimentos em infraestrutura de navegação regional como condição para a efetivaçáo da navegação fluvial amazônica. Em um terceiro momento, discute-se a função da IIRSA como instrumento de construção da infraestrutura necessária à navegação fluvial amazônica e, consequentemente, à integraçáo regional. Por fim, diante do abandono da IIRSA, em contradição com o projeto inicial de cooperação amazônica, adotando-se o método interpretativo e lógico-dedutivo, responde-se à questáo, identificando o processo de integração amazônica como um objetivo ligado a uma visão política mais progressista, que não se adéqua aos grupos conservadores, para quem basta uma cooperação amazônica simbólica.

\section{Importância ecológica da bacia hidrográfica amazônica}

Apesar de simbolizar a perfeição segundo uma visão ecológica da natureza, a Amazônia não pode ser analisada de modo deslocado, independentemente das atividades socioeconômicas ali implementadas tradicionalmente pelas populaçóes indígenas e ribeirinhas. Além disso, não se pode minimizar o fato de a Amazônia compor o território terrestre de diversos Estados, cuja soberania nacional é um atributo reconhecido como fundamento da construção do direito como um sistema unitário. A existência da soberania nacional de nove diferentes Estados sobre o espaço amazônico sempre significou para os Estados sul-americanos - e europeu - o direito de determinar livre e exclusivamente as estratégias e medidas a serem adotadas na gestão e conservação daquele espaço continental. Com efeito, Bolívia, Brasil, Colômbia, Equador, França, Guiana, Peru, Suriname e Venezuela detêm seu respectivo território amazônico.

Quando esses Estados percebem, no fim dos anos de 1960, que os fóruns de

5 Em 1977, o Estado brasileiro, por meio de seu Ministro das Relaçôes Exteriores, fez circular entre os demais Estados amazônicos um esboço de tratado internacional para a cooperação regional. Vide GARCIA, Beatriz. The Amazon from an International Law Perspective. New York: Cambridge University Press, 2011. 
discussão internacional, notadamente a Organização das Naçóes Unidas, passam a ser paulatinamente ocupados por demandas ambientalistas, opóem-se a esse processo, pois temiam que eventuais obrigaçôes internacionais ambientais pudessem comprometer o livre exercício de seus direitos soberanos territoriais. Como resposta, no âmbito interno, esses países decidem levar adiante projetos de exploração dos recursos naturais da Amazônia, que implicariam a ocupação populacional dos espaços vazios de seus territórios terrestres. A partir de uma visão antropocentrista do processo geopolítico internacional, fundada em concepções de segurança nacional típicas de regimes autoritários ${ }^{6}$, acreditava-se que espaços territoriais sem presença humana significativa poderiam ser objeto de internacionalização, o que significava uma ameaça à integridade territorial do Estado (TOLEDO, 2012).

Como desdobramento da implementação desses projetos, há uma corrida de gente para a Amazônia a fim de realizar os grandes empreendimentos capitalistas relacionados à extração de madeira, produção hidrelétrica, mineração e agropecuária (CHAVES, 2015). O resultado desse processo de ocupação acelerada da Amazônia é a destruiçáo da floresta pelo desmatamento, o aumento das queimadas como estratégia de preparação do solo para pastagens, a poluição dos cursos d'água pela atividade de mineraçấo legal e clandestina e o acirramento dos conflitos sociais. Em um período em que se confundia desenvolvimento econômico com destruição ambiental, não causa surpresa o fato de a utilização dos recursos naturais pelo Estado soberano ter sido uma catástrofe socioambiental. Em um período em que se espalhavam pela América Latina ditaduras criminosas, o ecossistema amazônico era visto como empecilho ao desenvolvimento socioeconômico nacional. Como os países desenvolvidos já tinham feito anteriormente, chegara a hora dos países subdesenvolvidos adotarem a mesma estratégia de destruição ambiental como condição para o desenvolvimento.

Com a realização da Conferência das Naçóes Unidas sobre Meio Ambiente Humano, em Estocolmo, em 1972, formula-se definitivamente o conceito de desenvolvimento ecológico em contraposição ao desenvolvimento econômico. Coincide com esse momento a percepçáo internacional do papel exercido pelo meio ambiente natural equilibrado como condição para a plena existência da humanidade como um todo, o que justificava a criação de um sistema jurídico internacional de proteção ambiental. Não é à toa que se identifica aqui o surgimento do direito internacional do meio ambiente como ramo próprio (SOARES, 2001).

Como desdobramento da sistematização jurídica ambiental, a Amazônia é identificada como um ecossistema importante para o equilíbrio ambiental global. Não se tratava de uma questão local, mas de um elemento que interessava a toda a humanidade. É aqui que se identifica o início da retomada de uma discussão 
internacional acerca da necessidade de instituir instrumentos efetivos de conservação da Amazônia, visando a sobrevivência do planeta (RIBEIRO, 2006, p. 221). Os impactos globais da destruição desse ecossistema localizado na América do Sul justificariam o sentimento de responsabilidade comum, que seria assumido especialmente pelos Estados desenvolvidos. Em suma, a Amazônia deveria ser internacionalizada, pois a vida de toda a humanidade depende de sua conservaçáo (TOLEDO; BIZAWU, 2019). Evidentemente, a lógica desse discurso deve ser entendida como um claro exemplo de iniciativa neocolonial, que, sustentada em dados científicos acerca dos impactos significativos da destruição ambiental, pretendia reproduzir imediatamente nos Estados amazônicos um modelo de gestão compatível com os interesses econômicos de grupos localizados nos países desenvolvidos.

\section{TCA: base jurídica de integração regional amazônica}

Como resposta às propostas de internacionalização da Amazônia, cujo sucesso dependia da implementação de um regime jurídico internacional específico, os Estados amazônicos decidem se antecipar, adotando, no âmbito regional, a mesma estratégia, qual seja o estabelecimento de um regime jurídico internacional amazônico, fundado na reafirmação de sua soberania territorial, mas sem menosprezar o consenso obtido em Estocolmo anos antes, que se refere ao reconhecimento da obrigação de cooperação internacional para a proteção ambiental. Contudo, no caso da Amazônia, a cooperação se daria exclusivamente entre os Estados em desenvolvimento, mantendo-se a França de fora do processo.

Em vez de restringirem-se a fortalecer unilateralmente sua soberania territorial, como vinha acontecendo desde a década anterior, decidem os Estados amazônicos subdesenvolvidos, por iniciativa do Brasil, trazer a questáo amazônica para a dimensão internacional, em um contexto de contraposição Sul-Norte. A partir da iniciativa brasileira, oito Estados amazônicos celebram, seis anos depois da Conferência de Estocolmo, o Tratado de Cooperação Amazônica, cujo objetivo central era reforçar a soberania nacional dos Estados sobre seu respectivo território amazônico, contrapondo-se frontalmente a qualquer tese de internacionalização da Amazônia.

Para tanto, o Tratado envolve não apenas os Estados ribeirinhos da bacia hidrográfica amazônica ou influenciados pelo bioma amazônico, mas aqueles que faziam parte do mundo em desenvolvimento, o que demonstra seu caráter geopolítico do TCA, em sua origem. De fato, Bolívia, Brasil, Colômbia, Equador, Guiana, Peru, Suriname e Venezuela são Estados membros do Tratado, ao passo 
que a França, que exerce a soberania territorial sobre o departamento ultramarino da Guiana Francesa, ficou de fora de suas negociaçóes. Não havia interesse dos Estados amazônicos do Sul em ter a participação de um Estado amazônico do Norte, que defendia teses pouco permeáveis à noçáo de soberania permanente sobre os recursos naturais (SOLA; COSTA, 2014).

O Tratado de Cooperação Amazônica correspondeu, então, a um importante instrumento internacional de reafirmação das soberanias nacionais sobre segmentos territoriais bem delimitados do espaço amazônico. A Pan-Amazônia é internacional, mas não internacionalizada.

Apesar de ter sido criado como antítese das pretensóes de internacionalização, o Tratado de Cooperação Amazônica não pode ser interpretado tão somente por esse viés. A importância desse instrumento internacional advém do fato de também representar uma iniciativa importante de integração regional daqueles Estados sul-americanos, voltada à cooperação política, econômica e ambiental. A ausência do termo "integração" em favor da "cooperaçáo" não pode ser vista como evidência de que não há, no sistema criado pelo Tratado, qualquer objetivo relacionado à integração amazônica. Com efeito, há diferenças conceituais entre cooperação e integração (MARIANO, 2007, p. 135). Este é um processo de interdependência estrutural programada entre Estados, o que exige um plano coordenando aprofundamento das interdependências socioeconômicas nacionais, que preveja medidas unilaterais sincronizadas internacionalmente. Já a cooperação é uma das condiçôes da integração, relacionada ao aspecto político-econômico. Logo, não há integração sem cooperação, mas esta não basta para haver integraçáo. Diante disso, a pergunta impóe-se: o TCA pode ser visto como um tratado de integração amazônica?

Segue-se o posicionamento doutrinário, segundo o qual o Tratado de Cooperação Amazônica, além de significar um firme posicionamento dos Estados sul-americanos em face da sociedade internacional - em especial dos Estados desenvolvidos -, caracteriza-se também por ser um primeiro mecanismo de integração regional. Tal elemento de integração regional pode ser identificado já no preâmbulo do Tratado, quando se estabelece:

[...] conjugar esforços [...] para promover o desenvolvimento harmônico da Amazônia, que permita uma distribuição equitativa dos benefícios desse desenvolvimento entre as Partes Contratantes, para elevar o nível de vida de seus povos e a fim de lograr a plena incorporação de seus territórios amazônicos às respectivas economias nacionais.

O Tratado de Cooperação Amazônica contém, portanto, elementos típicos do direito de integração, pois há ali a previsão expressa da obrigação de tomada 
de medidas coordenadas internacionalmente com vistas à redução das assimetrias socioeconômicas existentes entre as partes (SILVA; WANDERLEY JÚNIOR, 2015). No mesmo sentido, consta, como um dos dez princípios inscritos no Tratado, o princípio da busca constante pela integração.

Esse princípio jurídico pode ser identificado no art. VI do Tratado, que contém disposiçôes relativas à efetiva integraçấo física dos Estados amazônicos, ao prever medidas unilaterais, bilaterais ou multilaterais de melhoramento das vias navegáveis de conexão física dos Estados-partes entre si e destes com o Oceano Atlântico (CARVALHO, 2015). O referido art. VI assim estabelece:

Com o objetivo de que os rios amazônicos constituam um vínculo eficaz de comunicação entre as Partes Contratantes e com o Oceano Atlântico, os Estados ribeirinhos interessados num determinado problema que afete a navegaçăo livre e desimpedida empreenderão, conforme for o caso, ações nacionais, bilaterais ou multilaterais para o melhoramento e habilitação dessas vias navegáveis. [...] Para tal efeito, estudar-se-ấo as formas de eliminar os obstáculos físicos que dificultam ou impedem a referida navegação, assim como os aspectos econômicos e financeiros correspondentes, a fim de concretizar os meios operativos mais adequados.

Constata-se, portanto, que toda discussão sobre integraçáo regional amazônica perpassa necessariamente os aspectos referentes à navegação fluvial e sua infraestrutura. O Tratado de Cooperação Amazônica institui metas de desenvolvimento da Amazônia por meio de projetos de integração e utilização racional dos recursos hídricos. Não é por acaso que os Estados amazônicos identificam o transporte fluvial como instrumento de integraçáo regional.

\section{Integração regional amazônica pela navegaçáo fluvial}

A bacia hidrográfica amazônica representa uma vasta rede de cursos d'água navegáveis, sendo a mais extensa rede hidrográfica do planeta. Com uma área de milhões de quilômetros quadrados, distribuída em diversos territórios nacionais, a bacia hidrográfica amazônica tem cerca de 25.000 quilômetros de cursos d'água navegáveis (SILVA; DANTAS, 2012, p. 39). A quantidade de chuva torna seus rios permanentes e caudalosos, o que garante a possibilidade de navegação durante todo o ano. Por isso, a Amazônia tem forte potencial hidroviário.

$\mathrm{Na}$ Amazônia, onde há a maior concentração da água doce superficial, a 
navegação tem sido historicamente utilizada como alternativa de integração. $\mathrm{O}$ Rio Amazonas, que tem mais de mil afluentes, nasce na Cordilheira dos Andes, no Peru, atravessa o território brasileiro de oeste a leste, desaguando na foz do Oceano Atlântico $209.000 \mathrm{~m}^{3} / \mathrm{s}$ de água doce, o que representa quase $20 \%$ de todo o fluxo global de água fluvial de superfície (MOLINIER et al., 1994).

A navegação de cabotagem refere-se ao deslocamento de embarcação entre portos, conectando as rotas marítimas com as rotas navegáveis interiores. No que concerne à navegação interior, como o próprio nome indica, trata-se de navegação em cursos d'água nacionais ou internacionais, sendo a navegação de longo curso aquela que se dá entre portos nacionais e estrangeiros.

Quando se fala de integração amazônica por meio do incremento da navegação fluvial, fala-se em navegação interior em cursos d'água que compóem a bacia hidrográfica amazônica. Não apenas na Amazônia, mas especialmente ali, os cursos d'água e suas áreas de influência têm sido utilizados como elemento de cooperação e integração regionais. Em sua bacia, destacam-se as seguintes hidrovias: Amazonas, Branco, Juruá, Madeira, Marajó, Negro, Purus, Solimões, Tapajós, Trombetas e Xingu (MORGADO; PORTUGAL; MELLO, 2013). Os cursos d'água amazônicos apresentam diferentes condições de navegação, o que demanda uma atenção especial do Estado no que concerne à construção de infraestrutura.

Embarcaçôes, vindas dos oceanos, podem subir o Rio Amazonas até Iquitos, que se localiza a $3.700 \mathrm{Km}$ da foz. Na Amazônia, há mais de $50.000 \mathrm{Km}$ de hidrovias para embarcaçóes pesando até 1.000 toneladas, sendo que, em 10.000 $\mathrm{Km}$, é possível a navegação de embarcaçôes pesando mil toneladas ou mais. O Rio Amazonas tem, consequentemente, um grande potencial hidroviário (GARCIA, 2011).

De fato, o espaço geográfico de aplicação do Tratado de Cooperação Amazônica coincide com o maior eixo fluvial do planeta. Sendo assim, esse instrumento jurídico internacional póe ênfase na importância do aperfeiçoamento das condiçôes de navegabilidade dos cursos d'água amazônicos, sendo o planejamento integrado de infraestrutura de transportes, uma ferramenta para a adoção de políticas públicas em favor das populaçóes locais (RICUPERO, 1984).

Percebe-se, assim, que o Tratado apenas consolidou juridicamente uma situação de fato historicamente existente na bacia hidrográfica amazônica, qual seja o potencial fluvial para a realização de atividades comerciais e para a circulação de pessoas por embarcaçóes arvorando bandeira dos Estados ribeirinhos. Mesmo antes da celebraçáo do Tratado de 1978, inúmeros outros instrumentos jurídicos convencionais dispuseram, desde o século $\mathrm{XIX}^{7}$, de normas sobre a navegação

7 São tratados internacionais sobre a navegação de cursos d'água amazônicos, por exemplo, o Tratado sobre Comércio, Navegação e Fronteiras entre Brasil e Peru de 1851 e o Tratado de Amizade, Comércio, Navegação, Fronteiras 
fluvial de cursos d'água amazônicos (SILVEIRA, 2008). O Tratado de Cooperação Amazônica inova ao sustentar que a navegação fluvial amazônica não deve ser vista apenas como estratégia de desenvolvimento nacional de cada um dos Estados-partes, mas de integração regional.

Outro princípio do Tratado, identificado pela doutrina, é o princípio da liberdade de navegação. Embora não seja um princípio geral do direito internacional, há quem veja ali uma tendência à existência de uma concessão dessa liberdade (CARVALHO, 2015), o que não corresponde à internacionalização do curso d'água, como já acontece com o regime jurídico do mar territorial, onde existe o direito de passagem inocente de todas as embarcaçóes estrangeiras (MATTOS, 2014, p. 906).

No caso do sistema jurídico internacional amazônico, o princípio da liberdade de navegação encontra-se no art. III, e assegura, com base na reciprocidade, a mais ampla liberdade de navegação comercial no curso do Amazonas e demais rios amazônicos internacionais.

No que concerne à liberdade de navegação dos cursos d'água amazônicos, trata-se de característica do regime jurídico convencional, que corresponde a uma exceção ao princípio da integridade territorial, segundo o qual cada Estado é soberano para controlar a entrada, permanência e saída de seu território nacional. No que concerne ao regime jurídico de navegaçáo fluvial, instituído no Tratado de Cooperação Amazônica, é prevista a liberdade de navegação nos cursos d'água amazônicos das embarcaçóes dos Estados-partes, garantindo-se, assim, a reciprocidade entre eles. $\mathrm{O}$ Tratado não prevê em si mesmo a liberdade de navegação incondicional, mesmo em face dos Estados-partes, mas de um privilégio estabelecido para benefício próprio, sem alargar a exceção à embarcaçôes de Estados terceiros. Com efeito, trata-se de uma solução normativa internacional regional, adotada historicamente pelos Estados amazônicos, por meio da qual a liberdade de navegaçăo é garantida inter parties (GARCIA, 2011).

Identificado o potencial hidroviário da bacia hidrográfica amazônica, adotou-se o Tratado de Cooperaçáo Amazônica com a perspectiva de integração regional por meio da navegação fluvial. A fim de criar uma estrutura organizacional para garantir a aplicaçâo dos dispositivos convencionais, instituiu-se a Reunião dos Ministros das Relaçôes Exteriores (RMRE) como órgão deliberativo responsável por fixar diretrizes comuns, avaliar as iniciativas desenvolvidas e adotar decisóes necessárias à sua realização. Por sua vez, o Conselho de Cooperação Amazônica (CCA) dá apoio e suporte ao RMRE, sendo composto por representantes diplomáticos dos Estados-partes do Tratado. Compóe também sua estrutura organizacional a

e Extradição entre Brasil e Bolívia de 1867. 
Secretaria Permanente, sediada em Brasília, as Comissões Nacionais Permanentes, que são responsáveis pela aplicação do TCA nos respectivos territórios terrestres, e as Comissões Especiais destinadas à pesquisa de temas relevantes (CARVALHO; SILVA, 2015).

Apesar dos avanços alcançados com a aplicação do Tratado de Cooperação Amazônica, consubstanciados na conclusão da III Reunião do CCA, realizada em Brasília, em 1988, sobre a necessidade de adoção de uma regulamentação comum da livre navegação comercial nos rios amazônicos, com o intuito de harmonizar os sistemas de sinalização, segurança e controle da navegação na bacia amazônica (GARCIA, 2011), muitas discussóes não culminaram em resultados concretos, o que deixa aberta a necessidade de implementação de novas estratégias para a consecução do objetivo de realizar a integração amazônica por meio da navegação fluvial.

\section{OTCA-AECA e UNASUL-IIRSA: infraestrutura de navegaçáo para integração regional}

No processo de desenvolvimento de novos mecanismos de aprofundamento da integraçáo amazônica, os Estados-partes do Tratado de Cooperaçáo Amazônica decidiram dar um importante passo. Apesar de existir uma estrutura burocrática interna, o Tratado carecia de um órgão executor, que lhe desse capacidade de ação para alcançar seus objetivos. A fim de instituir tal órgão, as partes do Tratado firmaram em Caracas, em 1998, o Protocolo de Emenda com o intuito de reafirmar os princípios e objetivos do Tratado e, especialmente, dar origem à Organização do Tratado de Cooperação Amazônica (OTCA), sujeito de direito internacional, sediado em Brasília, com capacidade jurídica suficiente para aprofundar as estruturas de integração previstas no Tratado de Cooperação Amazônica. Esse aprofundamento consistiria, por meio da ação direta da OTCA, na construção de mecanismos técnicos e financeiros, bem como de estratégias comuns de integração regional com base no desenvolvimento sustentável e na participação efetiva de todos os Estados, sem discriminação. A dúvida que ainda persistia referia-se à capacidade da OTCA, por meio de sua envergadura institucional, para impulsionar as estratégias de integração regional amazônica, destacando-se os projetos de financiamento para a navegação fluvial (ANTIQUERA, 2006).

No que concerne a esses projetos de financiamento da integraçáo regional por incentivo à navegação fluvial, eles consistiriam em investimentos em infraestrutura de apoio à circulaçáo de todo tipo de embarcação, de modo a assegurar a livre circulaçáo de bens e - por que não? - pessoas, o que favoreceria o comércio de 
bens produzidos na regiáo, com menor custo ambiental, social e econômico (CARVALHO; SILVA, 2015). Para que uma profunda integração aconteça, é necessário não apenas que o transporte fluvial de bens e mercadorias seja incentivado, mas que a navegação fluvial seja também um veículo de aproximação das populaçôes amazônicas dos diversos Estados da Amazônia. Uma verdadeira integração regional não pode se restringir ao âmbito comercial.

Em consonância com a estratégia de aprofundamentos dos mecanismos de integração amazônica, em 2009, os Estados-membros da OTCA negociaram uma revisão de seus objetivos por meio da Agenda Estratégica de Cooperação Amazônica (AECA). O objetivo era fortalecer o processo de integração. Durante a X RMRE, ocorrida em Lima, os Estados aprovaram a AECA, a ser executada nos anos seguintes. Assim como havia sido feito em 1998, quando do Protocolo de Emenda, a AECA reafirmou os objetivos do Tratado de Cooperação Amazônica e reforçou o papel da OTCA em sua consecuçáo. Para tanto, a AECA prevê diversos planos estratégicos, conhecidos com eixos de abordagem, que devem ser realizados pela OTCA e os Estados-partes. Um desses diversos eixos de abordagem refere-se especificamente a incentivos à navegaçáo fluvial como um dos instrumentos de integração regional (SILVA, 2013, p. 548).

Em relação à navegação comercial, a AECA tem determinado o fortalecimento das atividades do grupo de trabalho sobre o Regulamento de Navegaçáo Comercial nos Rios da Amazônia (RNCRA) para a atualização e harmonização do transporte de carga e passageiros (CGEE, 2013, p. 59). De fato, no âmbito da AECA, o eixo de abordagem sobre navegaçáo fluvial amazônica consistiu no processo de cooperação e diálogo regional para a formulação e aprovaçáo de um Acordo de Navegação Comercial nos Rios da Amazônia, nos termos dos arts. III, V, VI e X do Tratado de Cooperaçáo Amazônica. Em 2010, um grupo de trabalho ad hoc foi constituído para levar a cabo estudos sobre o RNCRA. As informaçóes elaboradas por esse grupo de trabalho ad hoc têm sido utilizadas para fundamentar as negociaçôes do Acordo de Navegação Comercial nos Rios da Amazônia.

O eixo de abordagem sobre infraestrutura e transporte foi instituído para favorecer as negociaçóes entre os Estados-partes do Tratado e a OTCA em vista da criação de mecanismos estruturais de incorporação da região amazônica aos sistemas econômicos nacionais por meio de uma rede hidroviária em harmonia com a conservação ambiental. Contudo, a integração da Amazônia por meio da navegação fluvial enfrenta sérios desafios, cuja complexidade impede esses Estados de exercer sua soberania territorial sobre esse importante bioma, de realizá-la a contento sob a égide exclusiva da OTCA.

Por esse motivo, os mecanismos estruturais de navegação fluvial na Amazônia devem, quando possível, ser coordenados com as atividades com o Con- 
selho Sul-Americano de Infraestrutura e Planejamento (COSIPLAN) da União das Naçôes Sul-Americanas (UNASUL). É interessante perceber a existência, no contexto das relaçóes bilaterais entre organizaçóes internacionais, e a previsão na AECA da OTCA, de coordenação de projetos de infraestrutura de navegação fluvial como o COSIPLAN da UNASUL, pois abre um leque muito importante de oportunidades uniformes de investimento para atender o objetivo de curto prazo, que consiste no desenvolvimento de infraestrutura de transporte pelos cursos d'água da regiāo amazônica, coração da América do Sul. Assim, evita-se a duplicação de esforços, otimizando a disposiçấo de recursos.

Neste ponto, percebe-se a criação de um mecanismo institucional amazônico de conexão com uma organização de integração regional mais ampla, que é o caso da UNASUL. Dentro desse arranjo, no que concerne à infraestrutura de navegaçâo fluvial amazônica como instrumento de integração sul-americana, assume papel preponderante a Iniciativa para a Integraçáo da Infraestrutura Regional Sul-Americana (IIRSA), pois, em 2011, tornou-se órgão técnico do COSIPLAN da UNASUL.

Sublinha-se que a IIRSA se torna, no contexto amazônico, protagonista da construção de uma infraestrutura de conexão hidroviária para o escoamento das exportações da produção dos Estados membros da OTCA e da UNASUL em direção aos mercados consumidores do oriente - países asiáticos, especialmente China e Índia - e do ocidente - Estados Unidos. A IIRSA é uma arena de debate regional da qual participam Estados sul-americanos.

O principal objetivo da IIRSA é consolidar uma estrutura física fundamental para a criação de uma rede de conexão viária, aeroportuária e marítima entre os Estados da América do Sul, proporcionando uma maior integraçáo por meio da circulação de bens e pessoas. Assim como existe em relação à AECA, a ação da IIRSA foi organizada a partir de um plano espacial para seu programa de desenvolvimento, chamado de Eixos de Integração e Desenvolvimento (EID). Estes são resultado de uma análise profunda do planejamento territorial de implantação da infraestrutura (MATA DIZ; PAULA; SECCHES, 2016).

\section{IIRSA na Amazônia: ascensão e queda}

Os novos vetores que mais diretamente têm impactado a Amazônia estáo relacionados aos projetos de integraçáo física, elaborados no âmbito da IIRSA. Trata-se de uma importante iniciativa multilateral, criada em 2000 no âmbito da UNASUL, envolvendo investimentos de aproximadamente bilhôes de dólares (COSTA, 2015, p. 74). A institucionalização da IIRSA pretendia traçar novas 
bases para a integração regional na América do Sul (CASTRO, 2012, p. 46).

No que diz respeito diretamente à Amazônia, quatro EID, instituídos pela IIRSA, pretendem interligar o continente ao litoral. São eles o EID bioceânico do Amazonas, o EID Andino, o EID Peru-Brasil-Bolívia e o EID do Escudo Guianense, sendo que o primeiro é o principal (IPEA, 2011). Esse último eixo abarca a Regiāo Oriental da Venezuela, o arco norte de Brasil e a totalidade dos territórios da Guiana e do Suriname, eminentemente no sentido oeste-leste.

Esses EID amazônicos abrangem principalmente projetos rodoviários, hidroviários e portuários. Valendo-se de sua lógica geoeconômica, são propostas obras de facilitação da circulação entre Venezuela, Guiana e Suriname, instituindo-se um corredor de exportação. Os projetos de interconexáo entre Venezuela e Brasil caracterizam-se por ser destacados corredores de integração do norte do Brasil com o sul da Venezuela.

Essa região da Amazônia é de grande importância geopolítica, o que faz da interconexão Amazonas-Orenoco um dos projetos de infraestrutura mais importantes para os países do continente. De fato, esse espaço amazônico destaca-se pela riqueza de recursos naturais ali encontrada. Diversidade biológica, recursos hídricos subterrâneos e superficiais, energia e minérios são elementos estratégicos em um contexto de divisão internacional do trabalho. Ademais, Brasil e Venezuela compartilham a maior parte da Amazônia, área de importância global, que desperta interesses de diversos atores internacionais. No intuito de garantir a integração regional dessa área, prevê-se a implementaçáo de obras importantes como aquelas relativas à navegabilidade da hidrovia do Rio Negro até a fronteira com a Venezuela. A consolidaçáo do eixo estratégico entre Amazonas e Orenoco cria uma nova possibilidade de aproximação dos Estados da América do Sul com os países do Caribe, em um contexto em que a política externa para a integração regional amplia sua área de atuação sul-americana para outras regióes da América Latina e do Caribe (IPEA, 2011).

A infraestrutura de integração entre a bacia hidrográfica amazônica e a Bacia do Orenoco, se plenamente instalada, aproximará os produtores regionais de portos conectados a rotas internacionais estratégicas que passam pelo Caribe, potencializadas com o alargamento do Canal do Panamá, possibilitando maior articulação com os mercados do Oceano Pacífico. Essa aproximação depende significativamente da modernizaçấo da atividade de transporte fluvial, o que exige investimentos em infraestrutura.

Os Estados amazônicos deveriam investir em infraestrutura de transporte fluvial por intermédio das estruturas internacionais de integração regionais como a OTCA e a UNASUL, interligadas pela IIRSA. A instalação dessa infraestrutura 
de navegação permitiria uma conjuntura favorável a uma maior exploração dos recursos naturais locais, contribuindo para o desenvolvimento socioambiental da região e, consequentemente, do continente sul-americano. Esses tipos de organizaçôes internacionais em prol da integração física da região parecem obter muito mais investimentos do que a tradicional forma de cooperação amazônica, cujo objetivo principal era reafirmar as soberanias nacionais dos Estados sobre seus respectivos territórios terrestres.

Apesar da existência dessas organizaçóes internacionais e da importância de seus fóruns de discussão e projetos de infraestrutura, a integração amazônica continua a enfrentar muitas dificuldades, o que demanda dos Estados sul-americanos força política e criatividade econômica para dar tratamento à complexidade do problema.

A partir de meados da segunda década do século XXI, com a morte de Hugo Chávez na Venezuela, a eleição de Mauricio Macri na Argentina e a derrubada de Dilma Rousseff no Brasil, fatos que representaram uma significativa modificação da corrente política do continente sul-americano, a UNASUL passou a enfrentar um processo de forte desestabilização e enfraquecimento, que corresponderá ao fortalecimento da política externa argentino-brasileira contrária a qualquer iniciativa de cooperação multilateral ou integração regional (BARROS; GONÇALVES, 2019).

Não faz muito tempo, as partes da OTCA eram também partes da UNASUL e, consequentemente, participavam da IIRSA. Em 2019, acompanhando a Argentina, o Brasil denunciou o Tratado constitutivo da UNASUL, colocando fim à participação brasileira na organização, que passou a ser visto, em um contexto político marcadamente neofascista, como "institucionalização de viés ideológico de esquerda" (SIMÓES, 2019, p. 12).

Atualmente, o processo de integração sul-americana e, consequentemente, amazônica, enfrenta uma profunda crise. Projetos e perspectivas de desenvolvimento econômico, social e ambiental, que permitissem aos Estados da Amazônia reais possibilidades de superação do subdesenvolvimento em moldes verdadeiramente sustentáveis, nunca estiveram tão distantes.

Por meio da IIRSA, cujo papel de interligação entre UNASUL e OTCA é fundamental, tendo em vista as perspectivas de integração amazônica por meio de investimentos em infraestrutura de transporte fluvial, os Estados amazônicos teriam um instrumento estratégico para a consecuçáo dos objetivos inscritos no Tratado de Cooperação Amazônica. Contudo, a integração regional, construída de maneira autônoma, reafirmando a soberania nacional e fortalecendo a cooperação internacional, com base em planos estratégicos de fortalecimento conjunto, 
passa a dar lugar a uma visão de aversáo ao multilateralismo e apoio à subserviência neocolonial.

Ao colocar em risco a UNASUL, o que implica diretamente uma ameaça à IIRSA, cujo papel na integração amazônica é, na atual conjuntura, insubstituível, condena-se mais uma vez a Amazônia ao subdesenvolvimento predatório. Não é alheio a esse processo de desconstrução o aumento dos índices de destruição do ecossistema amazônico nos últimos anos. "A despeito de fazer parte de um ciclo conservador - que, como qualquer ciclo, deve findar-se - certamente sua retomada teria que ser conduzida em um novo contexto, muito mais debilitado e atrasado em relação a meados dos anos 2000" (JAEGER, 2019, p. 10).

\section{Conclusáo}

Em 1968, quando as Naçôes Unidas convocaram os Estados membros para uma primeira conferência internacional dedicada exclusivamente à proteção do meio ambiente natural, os países amazônicos, destacando-se o Brasil, reagiram implementando grandes empreendimentos madeireiros, hidrelétricos, mineradores e agropecuários em contraposição direta a qualquer abordagem ambientalista. A destruição da natureza era o preço do crescimento econômico, inexistindo país subdesenvolvido disposto a dispor do direito de se desenvolver.

Em 1972, quando da realizaçáo da Conferência de Estocolmo sobre o meio ambiente humano, o Brasil liderou o grupo de Estados que se opunham sistematicamente àquela pauta de negociaçôes, considerando-a uma estratégia internacional de sabotagem dos interesses nacionais. Vivia-se o auge do regime ditatorial brasileiro, período em que preocupaçôes com a segurança nacional motivavam o cometimento de crimes contra a humanidade, que permanecem impunes.

Em 1978, consolidados os princípios jurídicos ambientais da Declaração de Estocolmo, o Brasil liderou os demais Estados amazônicos subdesenvolvidos a negociar um tratado internacional de cooperação regional, com o intuito de reafirmar a soberania territorial de cada um deles sobre uma porção do ecossistema amazônico e instituir compromissos de cooperaçáo regional. Celebrou-se o Tratado de Cooperaçáo Amazônica, em vigor desde 1980. Em um contexto de contraposiçáo entre interesses do Norte e do Sul, a França, que é um país da Pan-Amazônia, não participou da construção do sistema jurídico internacional amazônico.

O Tratado de Cooperação Amazônica deve ser visto como um instrumento jurídico de integração regional, pois pretende distribuir equitativamente os benefícios do desenvolvimento entre todos os Estados-partes. Além disso, em razão de seu forte potencial hidroviário, nos termos de seu art. VI, para que os cursos 
d'água amazônicos sejam um vínculo eficaz de comunicação entre os Estadospartes com o Oceano Atlântico, os Estados ribeirinhos devem empreender açóes nacionais, bilaterais ou multilaterais para o melhoramento e habilitaçăo dessas vias navegáveis. Para tanto, os Estados ribeirinhos devem estudar estratégias de eliminação de obstáculos físicos, econômicos e financeiros, que prejudiquem a navegação fluvial e a consequente integração regional.

Como desdobramento do princípio da integração amazônica por meio da navegação fluvial, o Tratado de Cooperação Amazônica prevê a liberdade de navegação nos cursos d'água amazônicos das embarcaçóes arvorando o pavilhão de Estados-partes. A liberdade de navegação nos rios amazônicos internacionais deve respeitar o direito interno de cada Estado ribeirinho, o que exige a adoçáo de instrumentos internacionais de uniformização das legislaçôes nacionais. Para tanto, tem sido negociado, no âmbito da OTCA, um Acordo de Navegação Comercial nos Rios da Amazônia.

Além da uniformização, é necessária a construção de infraestrutura de navegação fluvial nos diversos Estados amazônicos ribeirinhos. No que concerne aos investimentos para infraestrutura e planejamento, a UNASUL tem se destacado, desde 2000, por levar adiante o plano de integração da infraestrutura física sul-americana por meio da IIRSA. Diante disso, a OTCA se aproximou da UNASUL em vista da coordenação de projetos de infraestrutura para a navegação fluvial na Amazônia. A década de 2005 a 2015 foi o período de maior desenvolvimento da IIRSA, o que coincidiu com a consolidação no poder central dos Estados sul-americanos de representantes de correntes políticas progressistas, eleitos todos democraticamente.

Com efeito, apesar das peculiaridades de cada grupo, todos se identificavam com a necessidade de melhoria das condiçóes sociais dos respectivos países, o que impulsionou discursos anti-imperialistas em que eram ressaltados os objetivos nacionalistas, populares e igualitários (AYERBE, 2008). Nesse contexto político, favoreceu-se a identificação do caráter de integração do sistema jurídico internacional amazônico. No âmbito da IIRSA, há quatro EID de conexão do continente ao litoral, em que se inserem os projetos ligados à navegação: EID bioceânico do Amazonas, o EID Andino, o EID Peru-Brasil-Bolívia e o EID do Escudo Guianense.

A partir de 2015, por conta da alteração do ambiente político regional, verifica-se uma deliberada iniciativa de desestabilizaçáo e enfraquecimento da UNASUL, o que, necessariamente, repercute negativamente na IIRSA, dificultando a realização dos projetos de infraestrutura, inclusive na Amazônia. Até recentemente, todos os Estados membros da OTCA eram membros da UNASUL. Tudo 
mudou rapidamente.

Percebe-se, assim, que, uma vez que representantes de grupos políticos conservadores chegam ao poder central dos Estados amazônicos, decide-se inviabilizar as iniciativas de integração, sem revogação do sistema jurídico amazônico, fundado no princípio da cooperação. Para essa corrente política, a cooperação amazônica, sem integração, é suficiente para fazer face às pressôes internacionais para a preservação da Amazônia, sem tocar nas estruturas neocoloniais com as quais estão comprometidas.

Muitos são os mecanismos internacionais que se relacionam, na regiẫo amazônica, com a intençáo de articular pautas comuns acordadas em diálogos regionais, intersetoriais e interinstitucionais, de modo a executar projetos de cunho social, ambiental e econômico, além de estabelecer uma referência de gestão local, que carecem, no entanto, de amadurecimento e aprimoramento para se tornarem instrumentos consistentes para consumação da integração regional. Indispensável, portanto, que os Estados amazônicos agreguem esforços para superar as imperfeiçóes que impendem a plena efetividade das propostas da OTCA e apontem um horizonte de compatibilidade para concretização dos planos cingidos.

Apesar dos desafios similares enfrentados pelos Estados-partes do Tratado de Cooperaçáo Amazônica, o expediente para potencializar o sistema hidroviário da bacia amazônica é um expressivo passo na direção de sustentar um modelo de governança local, propício para consolidar o complexo processo de integraçáo e cooperação na extensa hileia amazônica, com a articulação de políticas coordenadas supranacionais vinculadas à conservação dos recursos naturais e à promoção do desenvolvimento socioeconômico, no qual se inclui fomentos ao modal fluvial.

De todo modo, o avanço do processo de integração amazônica desenvolvimentista e sustentável depende de soluçóes conjuntas. O unilateralismo de outrora já demonstrou ser insuficiente para fazer face aos desafios contemporâneos. Para tanto, importante reforçar os mecanismos de integraçáo por meio da construção de infraestrutura.

A IIRSA, existente no âmbito da UNASUL, por muito tempo, pareceu ser uma excelente iniciativa, que se encontra atualmente em situaçáo de extrema fragilidade. Seu site não é atualizado desde 2017 e o COSIPLAN deixou de funcionar como conselho em 2019. O fim do CONSIPLAN corresponde, na prática, ao fim da IIRSA (PEREGALLI; PANEZ; AGUIAR, 2020). Que os países da Amazônia saibam retomar o rumo da integração, apesar das oposiçóes e compromissos com o neocolonialismo. Seu real desenvolvimento socioambiental depende disso. 


\section{Referências}

ANTIQUERA, D. C. A Amazônia e a politica externa brasileira: análise do Tratado de Cooperação Amazônica (TCA) e sua transformação em organização internacional (1978-2002). Dissertação (Mestrado) - Instituto de Filosofia e Ciências Humanas, Universidade Estadual de Campinas, Campinas, 2006.

AYERBE, L. F. Governos de esquerda na América Latina e a perspectiva da política externa dos EUA. Perspectivas, Araraquara, v. 33, p. 213-232, 2008.

BARROS, P. S.; GONÇALVES, J. B. Fragmentação da governança regional: o Grupo de Lima e a política externa brasileira (2017-2019). Mundo e Desenvolvimento - Revista do Instituto de Estudos Econômicos e Internacionais, São Paulo, v. 2, n. 3, 2019, p. 6-39.

CARVALHO, D. F. R.; SILVA, M. E. R. A. O Tratado de Cooperação Amazônica e a integração regional por meio da navegação nos rios da Amazônia. In: TOLEDO, A. P. A Amazônia no Direito Internacional. Belo Horizonte: Arraes, 2015. p. 74-90.

CARVALHO, D. F. R. A principiologia do Tratado de Cooperação Amazônica: elementos para uma unidade regional. In: TOLEDO, A. P. A Amazônia no Direito Internacional. Belo Horizonte: Arraes, 2015. p. 35-53.

CASTRO, E. Expansão da fronteira, megaprojetos de infraestrutura e integração sul-americana. Caderno CRH, Salvador, v. 25, n. 64, p. 45-61, 2012.

CGEE - CENTRO DE GESTÃO E ESTUDOS ESTRATÉGICOS. Brasil, América Latina e África: convergências geopolíticas e estratégicas de integração. Brasília, DF: CGEE, 2013. (Dimensôes estratégicas do desenvolvimento brasileiro, v. 3).

CHAVES, M. P. S. R. Relaçóes internacionais na Amazônia: experiência de cooperação. In: TOLEDO, A. P. A Amazônia no Direito Internacional. Belo Horizonte: Arraes, 2015. p. 1-25.

COSTA, W. M. O futuro da Gran Amazonía: um desafio para os sul-americanos. PAIAGUÁS: Revista de Estudos sobre a Amazônia e o Pacífico, Coxim, v. 1, n. 1, p. 71-81, 2015.

GARCIA, B. The Amazon from an International Law perspective. New York: Cambridge University Press, 2011.

IPEA. A integração de infraestrutura Brasil-Venezuela: a IIRSA (Integração da 
Infraestrutura Regional Sul-Americana) e o eixo Amazônia-Orenoco. Relatório de Pesquisa. Brasília, DF: IPEA, 2011.

JAEGER, B. C. Crise e colapso na Unasul: o desmantelamento da integraçáo sul-americana em tempos de ofensiva conservadora. Revista Conjuntura Austral, Porto Alegre, v. 10, n. 49, p. 5-12, 2019.

MARIANO, K. P. Globalização, integração e o Estado. Lua Nova, São Paulo, v. 71, p. 123-168, 2007.

MATA DIZ, J. B.; PAULA, M. P.; SECCHES, D. V. Os atores interestatais no desenvolvimento regional e a participação social: a atuação dos grupos argentinos nos projetos de infraestrutura da IIRSA e do FOCEM. Revista Direito GV, São Paulo, v. 12, n. 3, p. 776-809, 2016.

MATTOS, A. M. Marotta e a natureza jurídica do mar territorial: homenagem ao professor emérito Vicente Marotta Rangel. Revista da Faculdade de Direito da Universidade de São Paulo, São Paulo, v. 109, p. 905-912, 2014.

MOLINIER, M. et al. Hidrologia da bacia do rio Amazonas. A Água em Revista, Belo Horizonte, v. 2, n. 3, p. 31-36, 1994.

MORGADO, A. V.; PORTUGAL, L. S.; MELLO, A. J. R. Acessibilidade na regiáo amazônica através do transporte hidroviário. Journal of Transport Literature, v. 7, n. 2, p. 97-123, 2013.

PEREGALli, A.; PANEZ, A.; AGUIAR, D. 20 años de IIRSA en América del Sur: ¿quién celebra ahora?. Nodal, 1 set. 2020. Disponível em: https://www.nodal. am/2020/09/20-anos-de-iirsa-en-america-del-sur-quien-celebra-ahora-por-alessandro-peregalli-alexander-panez-y-diana-aguiar/. Acesso em: 30 out. 2020.

RIBEIRO, N. F. A questão geopolítica da Amazônia: da soberania difusa à soberania restrita. Belém: EDUFPA, 2006.

RICUPERO, R. O Tratado de Cooperação Amazônica. Revista da Informação Legislativa, Brasília, DF, v. 81, n. 21, p. 177-196, 1984.

SILVA, C. R. V.; WANDERLEY JÚNIOR, B. A Amazônia como espaço transnacional e o Tratado de Cooperação Amazônica. In: TOLEDO, A. P. A Amazônia no Direito Internacional. Belo Horizonte: Arraes, 2015. p. 26-34.

SILVA, R. I. O multilateralismo amazônico, entre êxitos geopolíticos e entraves executivos: trajetória do processo de cooperação de 1978 a 2012. Brazilian Journal of International Relations, Marília, v. 2, n. 3, p. 533-559, 2013. 
SILVA, S. T.; DANTAS, F. A. C. Águas na Amazônia e o Direito Ambiental Internacional. Revista NEJ, vol. 17, n. 1, 2012, pp. 39-47.

SILVEIRA, E. D. Socioambientalismo amazônico. Curitiba: Juruá, 2008.

SIMÓES, R. M. A modificação da postura brasileira na Unasul: da criação à formalização da saída do bloco (2008-2019). Revista Neiba, Cadernos Argentina-Brasil, Rio de Janeiro, v. 8, p. 1-8, 2019.

SOARES, G. F. S. Direito Internacional do Meio Ambiente: emergência, obrigaçóes e responsabilidades. São Paulo: Atlas, 2001.

SOLA, F; COSTA, J. A. F. Estrutura jurídica: alcance da Organização e do Tratado de Cooperação Amazônica. In: SILVEIRA, E. D.; CAMARGO, S. A. F. Socioambientalismo de fronteiras: relaçóes homem-ambiente na Amazônia. v. III. Curitiba: Juruá, 2014. p. 107-127.

TIILO NETO, P. Soberania e ingerência na Amazônia Brasileira. São Paulo: Plêiade, 2009.

TOLEDO, A. P. Amazônia: soberania ou internacionalizaçáo. Belo Horizonte: Arraes, 2012.

TOLEDO, A. P.; BIZAWU, K. Condições jurídicas internacionais de intervenção na Amazônia. Veredas do Direito, Belo Horizonte, v. 16, n. 36, p. 91-122, 2019. 